\title{
Nouvelle Manga, mon amour. Reflexiones sobre la narración gráfica de historias cotidianas
}

\author{
Olalla Hernández Ranz
}

\author{
They're writing songs of love but not for me \\ A lucky star above but not for me \\ With love to lead the way \\ I found more clouds of gray \\ than any Russian play could guarantee. \\ George and Ira Gershwin
}

Las primeras manifestaciones de la historieta se remontan a hace más de un siglo y, aunque en principio no estaban dirigidas a un lector juvenil, con el tiempo el cómic se ha ido consolidado como un medio que encuentra sus adeptos más acérrimos en este sector de la población. Su atractivo entre los lectores de estas edades ha hecho que algunos padres, educadores y profesionales del ámbito de la promoción de la lectura se planteen el porqué de dicha afición, llegando a conclusiones erróneas como la creencia de que se trata de una lectura menor, concebida para la pura distracción de quien los lee. El origen de esta creencia puede deberse a que los primeros tebeos publicados en suplementos de revistas, en forma de tiras cómicas, tenían como fin la crítica social a través de un humor satírico en la mayoría de los casos. Con el salto al álbum o a la novela gráfica, el tebeo ha conservado ese carácter cómico para quienes desconocen el medio; así, por un lado, la relación con lo humorístico que parece restar calidad y, por otro, el que sea un medio popular entre los chicos, hacen que quede relegado a un segundo plano dentro del panorama lector. Otro de los factores que puede haber influido en esta creencia es la escasez textual que, junto a un dibujo en muchos casos estereotipado, han generalizado opiniones que consideran una limitadísima gama de colores de todo el especro.

Will Eisner -reputado dibujante de cómics norteamericano- denomina a este medio el arte secuencial y, en la obra homónima, argumenta que:

el cómic book consiste en un montaje de palabras e imagen, y por tanto exige del lector el ejercicio tanto de su facultad visual como verbal. Las particularidades del dibujo (v.b., perspectiva, simetría, pinchada) y las particularidades de la literatura (v.b., gramática, argumento, sintaxis) se superponen unas a otras. La lectura del cómic-book es un acto de doble vertiente: percepción estética y recreación intelectual. (1996: 8) 
En pleno siglo XXI, el cómic ha recorrido ya una trayectoria suficiente como para asegurar que se trata de un medio de expresión formado por un conjunto de códigos propios que exigen, por parte del lector, el desarrollo de distintas destrezas intelectuales para lograr comprenderlos. La interpretación de la imagen secuenciada teniendo en cuenta la elipsis, la relación texto-imagen, la comprensión de la metáfora visual, la sintaxis de las viñetas o el uso del color para construir significados, son algunos de los ejemplos que demuestran la necesidad de ciertas habilidades lectoras para la comprensión de las obras. Dada su influencia social hoy en día, el cómic es un medio digno de análisis desde las perspectivas tanto de forma como de contenido. Miguel Ángel Muro afirma en su obra, Análisis e interpretación del cómic, que el tebeo es un medio de expresión en estrecha relación con la sociedad contemporánea; de hechoapunta el autor- "una de las condiciones más sobresalientes, la fragmentariedad, la interrupción de sus elementos, coincide con uno de los rasgos más definitorios de la posmodernidad” (2004: 16).

Dentro del mundo de la viñeta, desde las clásicas tiras cómicas periódicas en los años treinta, se han ido formando distintas corrientes representativas del medio con características propias del país en el que han surgido. Algunas de las más populares son la Bande Desinée en Francia y Bélgica, el cómic estadounidense y canadiense -con ejemplos que van desde el slice of life a las historietas de Superhéroes- y el manga procedente de Japón.

El manga es el cómic más consumido entre adolescentes occidentales y todo tipo de lectores en el resto de Asia. Manga, término utilizado para designar los tebeos japoneses, significa literalmente "dibujos caprichosos" o "garabatos". Este género se ha convertido en un fructífero producto de mercado que, más allá de restringirse al conjunto de las historias dibujadas y escritas en papel, se extiende a videojuegos, series de televisión, películas e incluso encuentra difusión por SMS. Su gran acogida entre el público infantil y juvenil se debe, principalmente, a la poderosa influencia que el anime, versión cinematográfica y televisiva del manga, ha ejercido entre los lectores durante su infancia, estableciendo sólidos referentes de una cultura aparentemente ajena. La adicción al manga preocupa a algunos mediadores por la supuesta carga violenta y sexual, así como por la baja calidad que habitualmente se atribuye a sus obras. Es cierto que algunas de estas obras reúnen características atribuidas a la literatura de consumo, tal como la concibe Gemma Lluch, quien la describe como una

cubierta con ilustraciones y colores estridentes [...] títulos y otros paratextos 
lingüísticos restringidos y repetitivos que juegan a menudo con la emotividad. Formato y paratextos se encuentran en relación directa con el libro, ya que reúnen las informaciones del libro, de esta manera anticipan al lector los hechos que acontecerán en el relato, le adelantan lo que encontrará para acosarlo de forma que el contrato de lectura que el texto realiza con el lector fija las cláusulas y las condiciones de manera clara antes de iniciar la lectura. En el nivel discursivo, se observa una tendencia doble: por una parte, a la repetición que contribuye a la producción de significados con un sentido claro y a menudo unívoco, como por otra, crea unas pautas de ritmo narrativo basado tanto en la relajación lectora como en los cambios de ritmo, con el objetivo de crear suspenso y mantener el interés del lector. (Lluch 2005: 138)

Sin embargo no todos los cómics japoneses son obras de consumo masivo y existen, dentro del panorama, ejemplos de gran valor.

Los orígenes del cómic asiático se remontan a hace más de un milenio. Existen murales y libros ilustrados en los que ya aparecen imágenes secuenciadas con grandes dosis de humor, basadas en la caricatura y la sátira. En el siglo XII rollos de pergamino ilustrados contaban historias que se narraban en voz alta de pueblo en pueblo con contenidos centrados en lo humorístico, alcanzando incluso la irreverencia. La mayoría de estos rollos, dibujos pertenecientes al monje japonés Toba, versaban sobre animales, temática sexual o escatológica.

El humor ha sido un recurso recurrente en las obras japonesas, así como el tratamiento de la vida cotidiana. Ambos se han reflejado en el arte y la literatura desde el principio, como se aprecia en el teatro kabuki o en la obra de Hokusai Katshuihika, uno de los más importantes retratistas de la figura humana y de la vida nipona de finales del siglo XVIII y principios del XIX. Tras la introducción de la historieta europea en Japón por el británico Charles Wirgman, corresponsal del Ilustrated London News a finales del siglo XIX y principios del XX, surgen obras como la del genial autor de cómic japonés Rakuten Kitazawa, quien marcará el inicio del manga tal y como lo entendemos en la actualidad.

Durante el siglo XIX, por influencia occidental, comenzaron a publicarse las primeras revistas humorísticas de crítica social con tiras cómicas. Revistas como Japan Punch, Marumaru Chimbun of Japan y Tobae of Japan eran algunas de las más conocidas entre los lectores. Las tiras cómicas aparecen en los periódicos asiáticos muy poco después de sus publicaciones en EEUU, a partir de 1890. Eran, en su mayoría, tiras eróticas, grotescas y basadas en el humor absurdo. Aunque en Asia existía el cómic antes de la Segunda Guerra Mundial, fue entre los años 50 y 60 cuando se instaló 
realmente en la sociedad nipona para iniciar una gran tradición que llega hasta nuestros días. En la actualidad y desde la Segunda Guerra Mundial el manga se desarrolla con una notable influencia estadounidense, pero conserva parte de la esencia artística japonesa del ukiyo-e, grabados tallados en madera entre los siglos XVII y XX, que retratan paisajes, el mundo de las artes o el erotismo humano.

\section{Desarrollo del manga en el marco de una sociedad hipermoderna}

Con el declive de la posmodernidad desapareció un periodo basado en el eclecticismo y en la interrelación de las artes que produjo, según Teresa Colomer, “un aumento de la autoconciencia en el arte en general y en la literatura en particular, una exploración de los límites y posibilidades del arte a partir de la tradición que las conforma”. Sin embargo, ya se fue. El filósofo francés Gilles Lipovetsky, en su obra Los tiempos Hipermodernos, afirma que la posmodernidad ha llegado a su fin:

el periodo posmoderno señala el advenimiento de una temporalidad social inédita, caracterizada por el aquí y ahora [...] El pos de lo posmoderno tenía los ojos puestos todavía en lo que quedaba atrás y se había declarado muerto, permitía pensar en una desaparición sin concretar en qué íbamos a convertirnos, como si se tratara de conservar una libertad nuevamente conquistada a impulsos de la disolución de los encuadramientos sociales, políticos e ideológicos. De aquí la suerte corrió. Esa época ha terminado. (Lipovetsky 2006: 54)

La hipermodernidad se aleja del pasado y mira hacia delante queriendo modernizar la propia modernidad. La globalización y las exigencias del mercado fusionan el mundo y agudizan la sensación de fragilidad producida por una pérdida creciente de las identidades que sostenían al individuo:

Hipercapitalismo, hiperclase, hiperpotencia, hiperterrorismo, hiperindividualismo, hipermercado, hipertexto ¿Habrá algo que no sea hiper? ¿Habrá algo que no revele una modernidad elevada a la enésima potencia?” (Lipovetsky 2006: 55)

Por otro lado el consumismo, una de las características de esta nueva sociedad, ha hecho del individuo según Gilles Lipovetsky un ser más consciente de los males ajenos, alguien más solidario pero también más frágil e inseguro.

En el arte y la literatura este sentido del consumo, como una de las necesidades vitales del individuo que sostiene temporalmente la sensación de felicidad, crea un estado de ilusión constante porque hasta las ideas tienen fecha de caducidad. De este modo, la sociedad actual mira la cultura como un producto de mercado más, que ha de abastecer sus necesidades básicas de contemplación. La lectura no está al margen de las 
influencias de la sociedad hipermoderna, de forma que todo medio de comunicación se ve afectado por las exigencias de la demanda de un lector vulnerable a la mercadotecnia empresarial que ofrece, en ocasiones, lecturas efímeras al servicio de las modas. Si el libro es mercancía, en contraposición a la visión elitista que se tenía de la lectura antaño, es lógico pensar que esta época experimenta el declive de la calidad de los materiales de lectura hacia productos de consumo que no logran satisfacer la competencia del lector literario. Pierre Bourdieu, teórico francés que ha trabajado las relaciones entre la cultura y el mercado, sostiene:

¿Es posible todavía, y será posible por mucho tiempo, hablar de producciones culturales y de cultura? A los que hacen el nuevo mundo de la comunicación, y que son hechos por él, les gusta referirse al problema de la velocidad, los flujos de información y las transacciones que se vuelven cada vez más rápidos, y sin duda tienen razón en parte cuando piensan en la circulación de la información y la rotación de los productos. Dicho esto, la lógica de la velocidad y la del lucro que se reúnen en la búsqueda de la máxima ganancia en el corto plazo (con el rating en el caso de la televisión, el éxito de venta en el del libro -y, muy evidentemente, el diario- el número de entradas vendidas en el de la película, me parecen incompatibles con la idea de cultura. Cuando, como decía Ernst Gombrich, se destruyen las condiciones ecológicas del arte, el arte y la cultura no tardan en morir. (Bourdieu 1999: 56)

El cómic japonés, uno de los géneros de mayor empuje comercial dentro del medio, sufre también las consecuencias de la situación actual pues se ha transformado en un producto de mercado al servicio de las modas, que satisface la pulsión del lector tanto en la sociedad nipona como en la europea. El consumo de manga en Japón demuestra que esta sociedad está más cerca de la hipermodernidad de lo que lo está Europa, que se aproxima velozmente, ya que los jóvenes de hoy parecen compartir los mismos referentes gracias a la globalización cultural.

Con la imposición de la sociedad de mercado, en el marco de la hipermodernidad la lectura en Japón ha dejado de ser un acto de recogimiento y soledad para convertirse en algo cotidiano y colectivo que se lee en la calle o en el metro y se sirve de impulsos primarios como la intriga para alimentar a sus adeptos con interminables series especializadas, de rápida digestión, que mantienen al lector enganchado durante largas temporadas. Ésta es, sin duda, una de las claves del éxito del manga en el mundo; además de la económicamente rentable edición primigenia, en la que las obras se publican en voluminosas revistas especializadas con papel de baja calidad, cuya lectura se consume y desecha con rapidez, hasta comprobar su éxito y pasar a editarse en series de bolsillo. Actualmente, con el auge del individualismo, se ha 
comprendido que para captar la atención del lector los contenidos de las obras han de mencionar sus inquietudes. Así, existe en Japón una especialización temática tal que cada gremio, edad y condición tienen un manga a su disposición para ocupar sus ratos de ocio. Estas subdivisiones producen historietas particularizadas hasta tal punto que podrían incluso considerarse obras a la carta.

Entre los cómics manga de manufactura japonesa destacamos algunos de los más populares:

-El Kodomo es un género dirigido a niños pequeños. Se caracteriza por su sencillez en las formas y el contenido.

-El Shounen está dirigido a lectores masculinos a partir de 10 años aproximadamente. Aunque concebido para chicos, algunas chicas también lo leen. Se caracteriza por centrarse en una acción trepidante que deja de lado las descripciones. Aunque hay peleas, la carga violenta no es importante y trata también el amor, pero siempre desde la perspectiva de alguien de esta edad.

Dentro del Shounen, encontramos varios subgéneros, como el Harem, el Spokon o el Moe. El primero incluye historias protagonizadas por chicos obligados a convivir con muchas jóvenes a la vez y en las que la propia situación provoca confusiones y situaciones de enredo muy cómicas

El Shôjo manga es otro de los grandes subgéneros, dirigido a chicas a partir de 11 años y cuyo tema principal es el amor. Normalmente la protagonista es una adolescente que reúne y sufre todos los tópicos que caracterizan esta etapa. Una de las variantes más importantes es el Maho Shôjo, en el que el personaje principal es una chica con poderes mágicos, por lo que, además de los problemas propios de su edad, tendrá que hacer frente a las dificultades que le plantea su propia identidad.

-El Hentai en occidente se identifica con la pornografía y el erotismo. Dentro del Hentai encontramos múltiples subgéneros que desarrollan diversas perversiones sexuales y van desde el Loli-con, centrado en el sexo con adolescentes, hasta el Tentacle-rape, protagonizado por monstruos horribles que poseen tentáculos con los que acosan a chicas indefensas.

-El Seinen es un género dirigido a un lector maduro. Las tramas son más complicadas y abordan temas políticos y sociales. El sexo y la violencia son más explícitos, aunque no llegan al extremo de obviedad que presenta el Hentai. Pese a que están concebidos para lectores masculinos, entre las féminas también encuentran algunas adeptas. 
-El Josei sería la contrapartida femenina del Seinen. Así pues, este género está destinado a mujeres adultas, y narra experiencias diarias más realistas que las que podemos encontrar en el Shôjo. Existen obras ambientadas en la vida de universitarios, el día a día de una mujer adulta trabajadora en sus distintas especialidades e incluso Josei para amas de casa.

La clasificación anterior tiene que ver, como venimos comentando, con el circuito de publicaciones más comerciales. Sin embargo en Japón, como en el resto del mundo, existen corrientes de creación alternativas que conforma una producción de obras menor, aunque cuyas propuestas respetan criterios de calidad y experimentación más cercanos al arte que en el caso de los géneros mencionados.

Desde finales de los años cincuenta, un nuevo género dentro del cómic manga llamado Gekiga viene publicando obras independientes con una temática adulta, en la mayoría de los casos, y un estética más cuidada. El autor más representativo durante esta época fue Yoshihiro Tatsumi, alguien comprometido con el medio y reacio a los criterios de consumo que comenzaban a instalarse en las publicaciones de la época. Desarrollado en profundidad hasta por autores como Osamu Tezuca durante los años 60 y 70, en obras como Adolf o Budha, el Gekiga fue conformándome como género con presencia, voz propia y público lector hasta nuestros días. Hoy el Gekiga -dicen- ha sido reemplazado por un nuevo género o movimiento artístico llamado Nouvelle Manga.

\section{Origen de la Nouvelle Manga}

El término Nouvelle Manga fue empleado por primera vez, según María José S. Bermejo (2007) por Kiyoshi Kusumi, el editor de la revista Comickers, para referirse a la obra de Frédéric Boilet. Las influencias en el trabajo del autor francés afincado en Japón. 


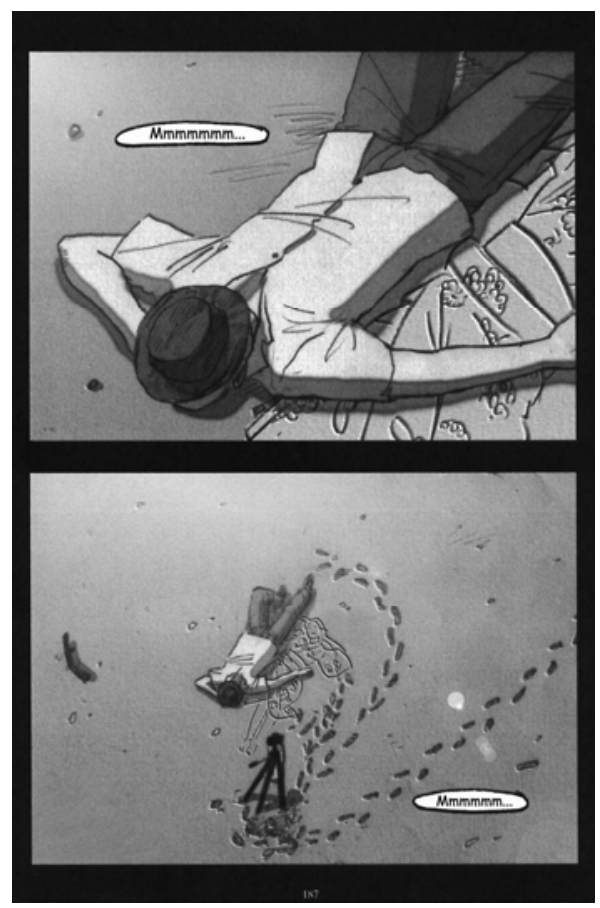

Figura 1: Ilustración del libro Mariko Parade de Frédéric Boilet Boilet y Kan Takahama. Alicante: Ponent Mon, 2007. El permiso para reproducir esta imagen es cortesía de la editorial Ponent Mont.

Poco después, Boilet lidera un proyecto que propone la Alianza Francesa junto a una conocida editorial: dibujantes, franceses y japoneses retratarán su experiencia vital en ciudades como Tokio, Kyoto, Sapporo, Osaka o Nagoya. A partir de sus vivencias en la ciudad elegida, los dibujantes francófonos construyen un relato de ficción autobiográfico en blanco y negro de 10 a 16 páginas. Por su parte, los autores japoneses retratan fragmentos vitales en su lugar de residencia.

Esta obra, publicada en España en 2006 por la editorial Ponent Mon con el nombre de Japón, no sólo ha reunido a algunos de los mejores dibujantes de cómic franceses como Aurélia Aurita, Frédéric Boilet, Nicolas de Crécy, Étienne Davodeau, Emmanuel Guibert, Fabrice Neaud, Benoît Peeters, David Prudhomme, François Schuiten y Joann Sfar y mangakas como Moyoko Anno, Little Fish, Kazuichi Hanawa, Daisuke Igarashi, Taiyo Matsumoto, Kan Takahama y Jiro Taniguchi, sino que además aporta al lector una visión clarificadora del nacimiento de un nuevo subgénero o movimiento artístico dentro del manga. La denominada Nouvelle Manga aúna la forma de contar historias de los dibujantes de cómic japoneses - quienes muestran sobrada fluidez narrativa además de destrezas técnicas en la transmisión de sensaciones y sentimientos concretos -, con las cualidades del cómic francés, que presta mayor 
atención a un dibujo de cuidada factura estética. La NM, cuyas características quedan patentes en el manifiesto redactado por el impulsor del movimiento y coordinador de Japón, insiste en la importancia de la creación de historias cotidianas, clave del éxito mundial del manga, para llegar a todo tipo de lectores. En su manifiesto, explica algunos de los rasgos principales del movimiento, que surge de la unión de dos de las corrientes más importantes del cómic:

Los cómics japoneses dan particular importancia a la historia (a la amplitud de las mismas, a la variedad de sus temas) y, especialmente, a la narración (a su fluidez, a las técnicas que se usan para sugerir sensaciones y sentimientos). En Japón, un mangaka es alguien que quiere, más que nada, contar historias, al contrario que los autores franceses de bande dessinée 'BD', quienes, generalmente, se convierten en artistas de cómic a través de un interés en el dibujo. (Boilet 2001)

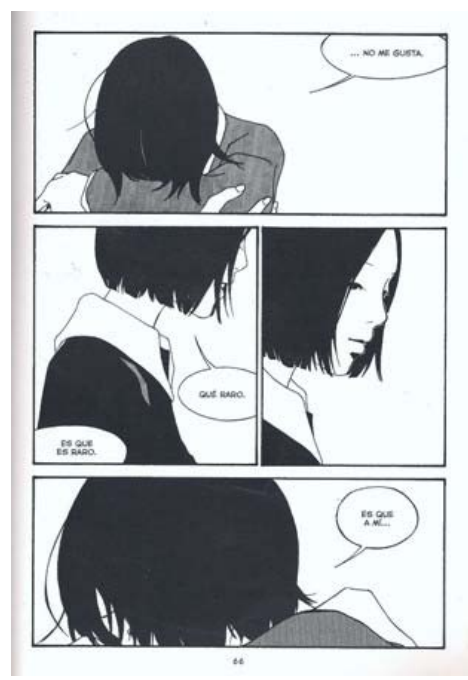

Figura 2: Ilustración del libro Blue de Kiriko Nananan. Alicante: Ponent Mon, 2004. El permiso para reproducir esta imagen es cortesía de la editorial Ponent Mont.

Pese a este afán universalista, la NM exige al lector cierta madurez, no sólo por sus contenidos sino también por la complejidad narrativa de algunas de sus obras, en las que la abundancia de elipsis y simbolismos requiere la constante participación lectora. La secuenciación es, por lo general, pausada y la transposición entre viñetas se detiene en aspectos concretos del entorno que ralentizan la acción de una trama eminentemente reflexiva, que el lector tendrá que construir añadiendo información de su propia experiencia.

“La manga sobre la vida cotidiana”, como Frédéric Boilet ha preferido llamar a este nuevo subgénero en contraposición a "el cómic manga”, pretende llegar a una 
audiencia europea más madura, alejada del otaku, fanático arquetípico del lector de manga que acostumbra a leer cómics donde imperan la acción, la exageración y los estereotipos. Por el contrario, Japón configura una obra de personalidad múltiple y total libertad creativa que aporta una doble visión del imperio del sol naciente: por un lado la del extranjero, visitante ocasional, y por otro, la de los propios japoneses.

\section{Herencias y características de la NM}

\section{Manga}

Su principal característica es la elección de la vida cotidiana como tema central en las obras que lo conforman. Un relato de amor lésbico entre dos adolescentes, la reconciliación con el pasado, la contemplación del mundo que nos rodea, historias de amor fallidas, abusos, relaciones familiares e incluso experiencias relacionadas con los propios procesos de creación son algunos ejemplos. Este rasgo fundamental de la NM bebe de la tradición del cómic japonés que ha desarrollado el día a día de cada uno de sus ciudadanos en distintas obras.

Por lo menos la mitad de los cómics japoneses narran historias de hombres y mujeres y sus vidas cotidianas. Esta adhesión a la vida cotidiana como tema es para mí la principal razón del éxito de la manga en una amplia variedad de lectores. Mientras los universos de ciencia ficción o de acción del cómic francobelga o americano están dirigidos casi en exclusiva a adolescentes masculinos, en Japón la manga de historias cotidianas llega de igual manera a hombres y mujeres, a adolescentes y adultos (Boilet 2001)

La sensualidad y el tratamiento del tema con abundantes referencias a asuntos sexuales dentro de las relaciones personales es otro de los puntos comunes que estas obras comparten con el manga. La herencia que aportan las primeras manifestaciones artísticas y literarias -como las elaboradas por el monje japonés Toba en sus Yobutsu Kurabe, centradas en la reproducción de la vida sexual así como el erotismo del ukiyoe- avalan una preferencia recurrente en las obras de manga para adultos en la actualidad.

Estas historias se centran en las emociones. Narran de instante en instante y con una potente carga simbólica los sentimientos de sus protagonistas frente a situaciones varias. Sin embargo, y pese a que el secuenciado no sea lineal, la pericia nipona a la hora de narrar hace que la elipsis no suponga ningún obstáculo para la comprensión lectora. Esta técnica permite trazar relaciones de empatía con los personajes a la vez que reflexionamos sobre los sucesos que les acontecen aquí y ahora. 
La brevedad textual es otra de las características heredadas del manga. Su ausencia, en ocasiones, como en el caso de la novela gráfica de Jiro Taniguchi El Caminante, deja toda la responsabilidad de transmisión de significado en manos de la narración de la imagen. El esfuerzo del lector es, en estos casos, directamente proporcional a su implicación en la búsqueda de sentido y su relación, por ende, más estrecha.

\section{Nouvelle Bande Desinée}

Durante los años 90, editoriales como l'Association impulsan la evolución de la BD, renovando aspectos de sus obras aunque manteniendo sus raíces. Algunos autores franceses como Joann Sfar, David B, Aurélia Aurita, Etienne Davodeau, Nicolas de Crécy, Emmanuel Guibert o Benoít Peeters, se distancian de las recurrentes aventuras fantásticas dirigidas al público juvenil para ofrecer lecturas realistas más maduras de carácter reflexivo, conformando un nuevo subgénero llamado Nouvelle Bande Desinée.

Otra de las aportaciones significativas, además del carácter autobiográfico, de la BD a la NM es la atención prestada a la imagen en cada una de sus obras.

Comparada con la manga, la BD pone más énfasis en el dibujo. Sus autores son, principalmente y sobre todo, ilustradores, a menudo más preocupados por el aspecto gráfico, que por el guión. Los lectores son los primeros en confirmar este «énfasis» puesto en el aspecto gráfico: un álbum de dibujo hábil o moderno siempre encontrará compradores en Francia, incluso si la historia es mala o estúpida. (Boilet 2001)

\section{Nouvelle Vague}

El término Nouvelle Vague fue acuñado por la crítica para designar una nueva corriente dentro del cine francés que surgió a finales los años 50 en contraposición al cinéma de qualité. Este grupo de cineastas pretendían una renovación del medio basado en la reproducción de la máxima objetividad a partir de la total libertad tanto técnica como artística. Como afirma el crítico y fundador de la revista de cine Cahiers du Cinéma, André Bazin, “el poder de reproducir exactamente, ingenuamente, es el mejor privilegio del cine” (1959: 37). André Bazin, -al igual que lo está haciendo F. Boilet en los tiempos que corren con la NM- trató de impulsar un nuevo movimiento dentro del medio que rompiera con la concepción vigente hasta entonces. Ambos autores parten de la libertad creadora para realizar un retrato fiel de la cotidianidad de la vida. La belleza de una historia, según ellos, reside en su relación de fidelidad con la realidad.

El cine usa técnicas que son instrumentos de reproducción o, si se prefiere, de conocimiento. Posee, de alguna manera, la verdad del golpe y se propone la 
belleza como fin supremo. Una belleza, y esto es importante, que no está en él sino en la naturaleza. Una belleza que tiene la misión de no inventar, sino de descubrir, de capturar como si fuese una presa, casi de robársela a las cosas. La dificultad suya no es, como se cree, forjar un mundo con esos espejos tan puros que constituyen sus herramientas, sino poder copiar de la mejor forma posible la belleza natural del mundo. (Bazin 1961: 83-84)

El retrato de la vida cotidiana que el manga ha desarrollado durante años tiene como fin para F. Boilet la universalidad. Las distintas temáticas elegidas empatizan con diferentes lectores por el poder de identificación con lo que está sucediendo y, aunque el dibujante no hace referencia al tratamiento objetivo de la ficción en su manifiesto, sí afirma:

Es paradójico que la vida cotidiana, el tema favorito del cine francés, y del cine europeo en general (perceptiblemente, en contraposición al cine de Hollywood), haya estado ausente de la BD durante mucho tiempo, mientras que siempre ha sido un tema preferido de la manga. (Boilet 2001)

Por otro lado, abandonando ligeramente el contenido de las obras, descubrimos similitudes en el propósito de ambas iniciativas. La necesidad de formar un movimiento artístico o comunicativo en contraste con las formas establecidas para ambos géneros, deja al descubierto una clara intención de denuncia. Boilet, por su parte, rechaza la superproducción de obras de consumo en el manga, la baja calidad de las mismas y sus temáticas, basadas en la acción y el movimiento frenético que reflejan la sociedad actual. Ambos movimientos, NM y NV reclaman quietud y reflexión ante el caos.

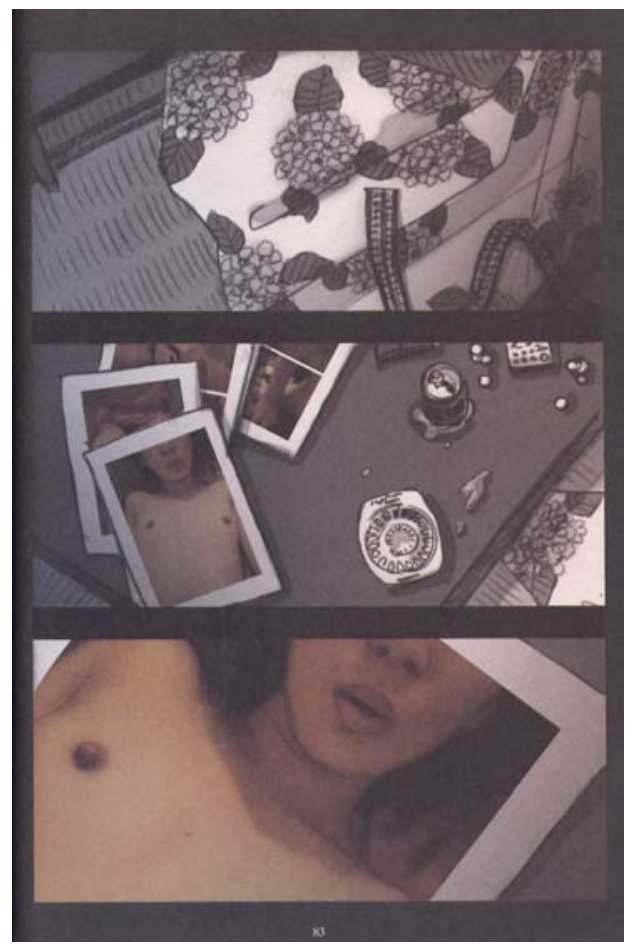

Figura 3: Ilustración del libro Mariko Parade. Frédéric Boilet y Kan Takahama. Alicante: Ponent Mon, 2007. El premiso para reproducir esta imagen es cortesía de la editorial Ponent Mont. 
Debido a su formación intelectual, los autores pueden observar de forma crítica la oferta del mercado y proponer una alternativa a quienes no sólo deseen formarse como lectores literarios: a través de sus obras, el lector encuentra arquetipos recurrentes como la duda existencial, la vuelta a la infancia, la relación del hombre con la madre naturaleza, o la reconciliación con el pasado, vinculados con intereses colectivos e inherentes a la condición humana. Las obras proponen también el autoconocimiento a través del arte. Tanto los realizadores de la NV como los autores de NM se incluyen en sus obras con el objetivo no sólo de proporcionar la máxima verosimilitud, sino como un experimento artístico metaficcional.

En cuanto a las técnicas empleadas para la creación de las obras de ambos movimientos, encontramos, de igual modo, similitudes formales. Se trata de productos muy personales que a pesar de las intenciones ofrecen la visión del autor. La libertad que proclamaban los cineastas de NV les permitió enfocar el cine desde su propia perspectiva, rodando en exteriores con pocos medios y luz natural. Así, los autores de NM prescinden de la abundancia de diálogos, complicando de alguna forma la identificación del lector con los personajes y narrando a través de la imagen sólo cubierta por tramas en blanco y negro. La NM reproduce en viñetas los movimientos de cámara típicos del cine y el ojo del lector recorre la página que simula un barrido o un zoom. La viñeta se viste de pantalla de cine en formato cinemascópico y sus imágenestambién en blanco y negro- simulando ser fotogramas filmados en cámaras de 16 mm., logran el objetivo de mostrar- al igual que en el cine de la NV- mayor ligereza y movimiento.

\section{A modo de conclusión}

El manga ofrece una amplia variedad de subgéneros especializados que intentan responder a un amplio abanico de intereses de los diversos lectores a los que va dirigido. Esta característica, única en el panorama del cómic universal, ha hecho que las historietas japonesas trasciendan fronteras y seduzcan a los lectores occidentales. Su infinita variedad de temáticas, los mecanismos narrativos de los que se sirve para captar la atención de lector, y las altas dosis de intriga repartida en los numerosos volúmenes que conforman cada obra, han encandilado sobre todo a adolescentes y niños cada vez más jóvenes. Por otro lado, la poderosa influencia de la versión audiovisual del manga, 
el anime, crea referencias globales entre los lectores de todo el mundo, asegurando su éxito como producto de mercado.

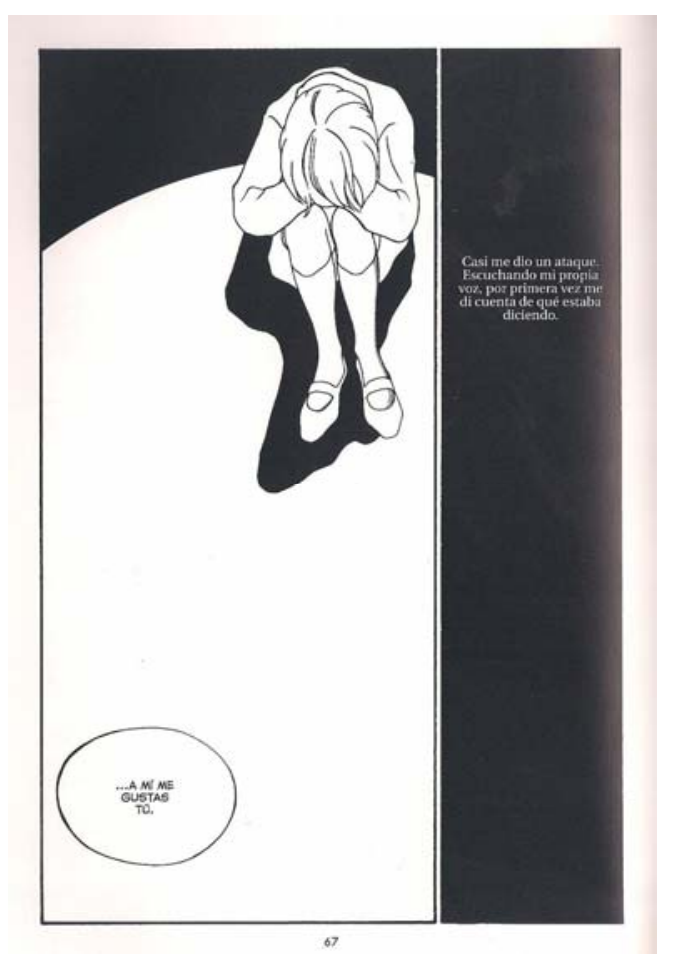

Figura 4: Ilustración del libro Blue de Kiriko Nananan. Alicante: Ponent Mon, 2004. El permiso para reproducir esta imagen es cortesía de la editorial Ponent Mont.

La Nouvelle Manga surge como reacción contra la actual concepción comercial de la lectura. La labor de Frédéric Boilet, en su intento de crear un cómic de calidad dirigido a un lector experimentado que ayude a construir su lectura, se ha logrado con éxito. La comunicación entre el autor de NM y sus lectores es fluida pero exigente a la vez, lo que conduce a quien lee hacia su yo interno para reconocer lo que sabe y concientizarse de realidades que ya le pertenecían.

La NM supone, por tanto, un salto gigantesco en la evolución del cómic nipón. Con ella se ha abandonado el chiste fácil y el humor escatológico para abordar una lectura más reflexiva, ambiciosa, que se propone llegar al interior del lector y conmoverlo. Además, forma al lector literario con sus abundantes referencias y carácter metaficcional y le educa estéticamente con una propuesta gráfica de alta calidad con la que la NM se aleja del dibujo estereotipado y caricaturesco que abunda en el manga en general. 
Todas las culturas poseen una gran suma de relatos compartidos, y la razón de su existencia reside en la necesidad primaria de contar y recibir historias que hablen de uno mismo, que acompaña al hombre a lo largo de toda su vida. El cómic no es más que otra fórmula de expresión escrita de historias que Boilet califica como universales. Aidan Chambers (2006) reflexiona intensamente sobre idea de lectura como el alimento espiritual del hombre que cierra esta investigación con sabias palabras:

Todas las culturas, letradas y no letradas, tienen un gran repertorio de relatos, así como cada individuo, letrado o no, tiene la memoria llena de ellos. Los relatos nos persiguen, nos juegan, nos leen, nos cuentan, nos hacen. Sin ellos, no somos nada. No existimos. Somos los relatos que contamos. Y en nuestra cultura actual existimos individualmente y como especie sólo a través de los relatos que escribimos. (2006: 39)

Hoy sólo queda esperar para descubrir de qué manera, la Nouvelle Manga, sensual, con su olor a humo y canciones interpretadas por Chet Baker, contribuirá a crear con sus códigos e imaginarios transculturales la identidad de los individuos de las generaciones futuras. De momento nos ha despertado la nostalgia por lo no vivido.

\section{Referencias bibliográficas}

Aurita, A. (2005-2007) Fresa y Chocolate I/II. Alicante: Ponent Mon.

Boilet, F. (2003) La espinaca de Yukiko. Alicante: Ponent Mon.

Bazin, A. (1959) La somme d’Ádré Bazin, Cahiers, 91.

Bazin, A. (1961) Le Gout de la beauté, Cahiers, 121.

Bermejo, M. (2007) Nouvelle manga. Fandelcomix. Disponible en:

http://www.fandecomix.com/index.php?option=com_content\&task=view\&id=841\&Ite $\operatorname{mid}=28$

Boilet, F. (2001) Manifiesto de la Nouvelle Manga. Disponible en: http://www.boilet.net/es/nouvellemanga_manifeste_1.html

Bourdieu, P. (1999) Más ganancias, menos cultura. Clarín. 24, noviembre. Visto en: http://www.clarin.com/diario/1999/11/24/i-02101d.htm

Chambers, A. (2006) Lecturas. México: Fondo de Cultura Económica.

Eisner, W. (1996) El cómic y el arte secuencial. Barcelona: Norma.

Lipovetsky, G. (2006) Los tiempos Hipermodernos. Madrid: Anagrama.

Lluch, G. (2005) Mecanismos de adicción en la literatura juvenil comercial. Anuario de Investigación en Literatura Infantil y Juvenil, 3. Valencia: Universidad de Valencia.

Muro, M. Á. (2004) Análisis e interpretación del cómic. Ensayo de metodología semiótica. Logroño: Universidad de la Rioja

Takahama, K. (2003) Kinderbook. Alicante: Ponent Mon.

Taniguchi, J. (2003) Barrio Lejano. Alicante: Ponent Mon.

Taniguchi., J. (2004) El Caminante. Alicante: Ponent Mon.

Referencias de la autora:

Olalla Hernández Ranz es licenciada en Filología por la Universidad de Salamanca. Cursó el Máster de libros y LIJ que imparte la UAB en su primera edición. Ha trabajado durante cinco 
años en el Centro Internacional del Libro Infantil y Juvenil de la Fundación Germán Sánchez Ruipérez, en el área de promoción de la lectura. Actualmente ha cambiado su lugar de residencia a Asturias, donde es librera y se dedica a la investigación y formación de profesorado y personal de biblioteca en relación a la promoción de la lectura y la narración gráfica. Colabora, además, con el diario El Comercio en la coordinación de un nuevo espacio web para chicos y jóvenes y escribe los guiones de la tira cómica, el Raitán, que se publican en el suplemento dominical de dicho periódico.

E-mail Olallah@gmail.com 